$\mathrm{Cu}-\mathrm{Ti}-\mathrm{B}$ 粉末のメカニカルアロイング過程に及ばすボロン添加量の影響

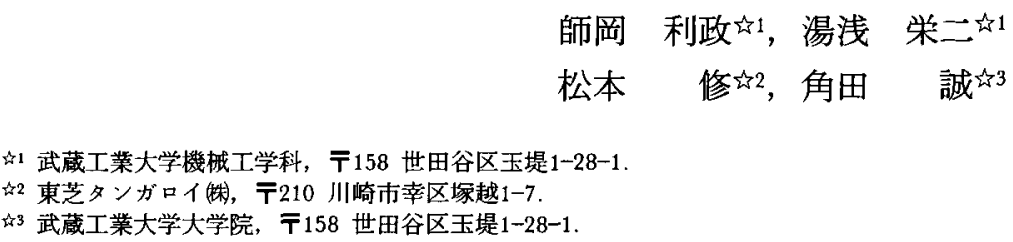

\title{
Influence of Boron Content on the Mechanical Alloying of Cu-Ti-B Powders
}

\author{
Toshimasa Morooka ${ }^{\text {s1 }}$, Eiji Yuasa ${ }^{\text {\$1 } 1}$ \\ Osamu Matsumoto ${ }^{\hbar 2}$ and Makoto Tsunoda \\ 41 Department of Mechanical Engineering, Musashi Institute of Technology, 1-28-1 Tamazutsumi Setagaya-ku, \\ Tokyo 158. \\ \$2 Toshiba Tungaloy Co., Ltd., 1-7 Tsukagoshi Saiwai-ku, Kawasaki 210 \\ \$3 Graduate School, Musashi Institute of Technology, 1-28-1 Tamazutsumi Setagaya-ku, Tokyo 158.
}

Received June 17, 1993

Mechanical alloying teratment of mixtures of elemental copper, titanium and boron powders containing various amounts of boron was carried out by using high energy ball mill. For comparisons, the treatment of mixture of alloy powder prepared from $\mathrm{Cu}-8 \mathrm{mass} \% \mathrm{Ti}$ cast and the boron powder was also carried out. Influence of boron content on the formation of boride titanium during the mechanical alloying and subsequent heat treatment was examined. In the powder prepared from the mixture of elemental powders, $\alpha$-solid solution and nonequilibrium $\mathrm{Cu}-\mathrm{Ti}$ phase are formed during the mechanical alloying. When the powder was heat-treated at $1173 \mathrm{~K}$, the noneruilibrium phase disappears, and equilibrium $\mathrm{Cu}_{3} \mathrm{Ti}$ phase and ultrafine spherical boride titanium particles are formed. $\mathrm{Ti}_{3} \mathrm{~B}_{4}$ and $\mathrm{TiB}_{2}$ particles are formed in the case of mixture with low contents of boron, but only $\mathrm{TiB}_{2}$ is formed from the mixture with high boron contents. The nonequilibrium $\mathrm{Cu}$-Ti phase is also formed by the mechanical alloying in the powder prepared from the $\mathrm{Cu}-\mathrm{Ti}$ cast, but the quantity of that phase is less than that of the powder prepared from the mixture of elemental powders.

\section{1 緒 言}

著者らは，これまでの研究で，Cu，Ti，B の混命粉 末をメカニカルアロイング（MA）し，そのMA遇程

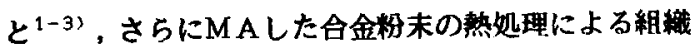

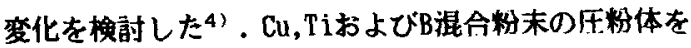
反応焼結すると、TiとB が反応して負に大きい標準生 成自由エネルギーをもつTiB 2 が形成する ${ }^{5)}$ ．またモル
比が1/2のTi-B混合粉末をMAすると，固相反心によ つてもTiB が牛成する5). しかし Cu-Ti-B混合粉末の MA過程ではTiB 2 を形成するとともに (CU-Ti) 合金相 も生成するので，これらの牛成相に対しTi/Bの配合比 が影響するものと思われる、そこで本研究はMA邀程

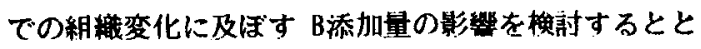
もに，素地組䄉とほう化チタン生成の関係も調查した。 


\section{2 実等方法}

原料粉末は市販の電解銅粉，遺元チタン粉およびほ う秦粉を用いた。これらの粉末を素地緗成として Cu8mass\%Tiに配合しここれに0〜8mass\%の種々のB量を添 加した。Cu-8mass\%Ti溶製(I/M)材の粉末はCu-25mass\% Ti册合金と絊銅地金をアルゴン雾国気で溶解して金型 鋳造し，1073Kで18ks均哲化処理した後やすりで削り 慗作した。MA処理はこれまでの研究 ${ }^{3 !}$.4! と同侎な 方法で72ksまで行った。各粉末は元素粉末Cu，Tiおよ びBの混合粉末を72ksM ALたものをPowder〈A〉，Cu8mass\%Tiの元素混合粉末を72ksMAL，このMA粉末 にBを添加してさらに72ksMAしたものをPowder〈B〉， Cu-8mass\%Ti侖金l/M粉末を $1173 K て ゙ 72 \mathrm{ks}$ 保持後水娔入 れしたものにBを添加して72ksMAしたものをPowder $\langle\mathrm{C}\rangle, \mathrm{Cu}-8 \mathrm{mas} \% \mathrm{Ti}$ 合金I/M粉末を1173K，72ks保持炉冷 の焼なまし処理したものに Bを添加して72ksM Aした ものをPowder $\langle\mathrm{D}>$ とした。

各粉末の熱処理は試料粉末を銅管で包み，石英管に 入れて真空寒用気にして，573〜1173Kて皏々の時間保 持した啳水冾して行った。

\section{3 実駼結果及び考察}

\section{3. $1 \mathrm{MA}$ 粉末の時効砶化}

Powder〈A〉について，MAしたままと 1173Kで72ks 保持後水冷の熱好理した粉末のビッカース䂺さとB添 加量との関係をFig.1に示す.MA粉末はB添加量が增 すにしたがって硬さは增加し，4mass\%以たでほぼ一定 の硬さとなる、MAによる加T硬化がB添加量に依存 しないならば，Cu相中へTiおよびBの蚛制固溶による

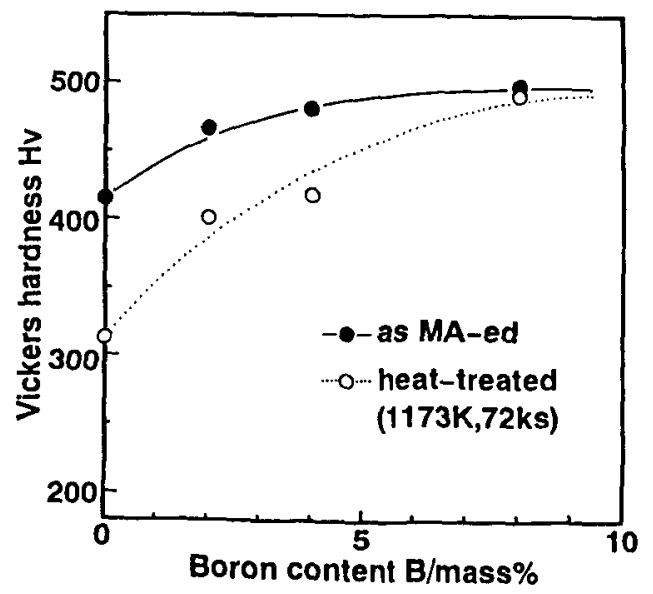

Fig.1 Change of Vickers hardness with boroncontent in the powder $\langle A\rangle$.
妻地の固溶体㹬化あるいはほう化チタン形成による分 散硬化はCu-8mass\%T门に対し4mass\%B添加が下限である と考えられる．MA粦末を熱处理すると加工硬化が除 去されて軟化する。しかしその軟化量はB添加量が增 すと減少する。

種々のB量を添加したPowder $<A>$ 〉 873Kで時効した ときの 時効時間に伴うビッカース硬さの変化をFig.2 に示す、いずれのB添加量のM A 粉末も短時間で䂺さ

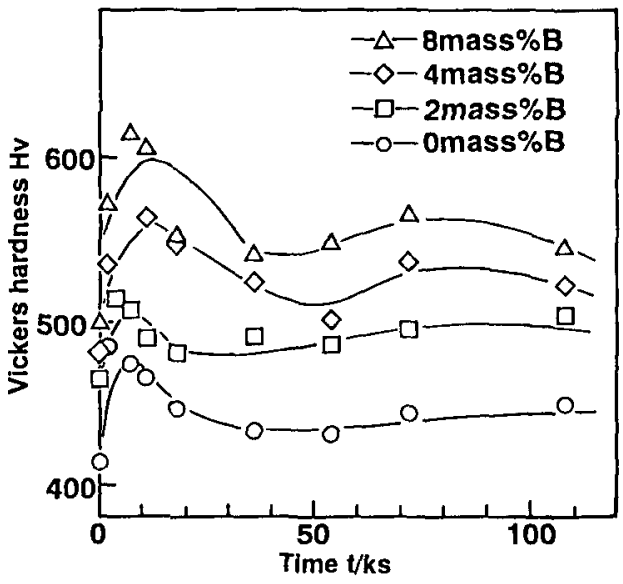

Fig. 2 Change of Vickers hardness with aging time at $873 \mathrm{~K}$ in the powder $\langle A\rangle$ with various boron contents.

は卜昇し，約20ksで䂺さの椣大值に達する。これらの 硬化量はB添加量にかかわらずほぼ一定であった。M $\mathrm{A}$ 粉末の時勃初期では（Cu-Ti）合金の素地に变調構造 をもつゾーンが形成し，硬さがト昇する゙．したがっ てこのような組織变化には B添加量が奇与しないこと を示している.Bを添加したM A 粦末は 長時間時效す ると第 2 の硬さの極大值が生じ，これらの硬化量は8 添加量が增すにしたがつて増大する，第2の砶さの板 大值はTiB のであり" 量が增加したものと思われる。

\section{3・2 MA粉末の組織と㙓㓳理による変化}

種々のB量を添加した Powderく A >のM A粉末のX 線 回折結果をFig.3に示す．いずれのB量の粉末もTiおよ びBの回折線は消滅し， $\alpha$-Cu相の回折線と2 $\theta=35 \sim 38$ deg.に低強度の回折線が観察された。これらの回折線 はJ C P D Sカードによって同定されず，B を添加し ていない粉末にも存在するので，M A遇程で生成した 非平衡 $(\mathrm{Cu}-\mathrm{Ti}$ ) 相と思われる。また $\alpha-\mathrm{Cu}$ 相の格子定数 は，いずれの B添加量の粉末も，MA前の36.154nmか 


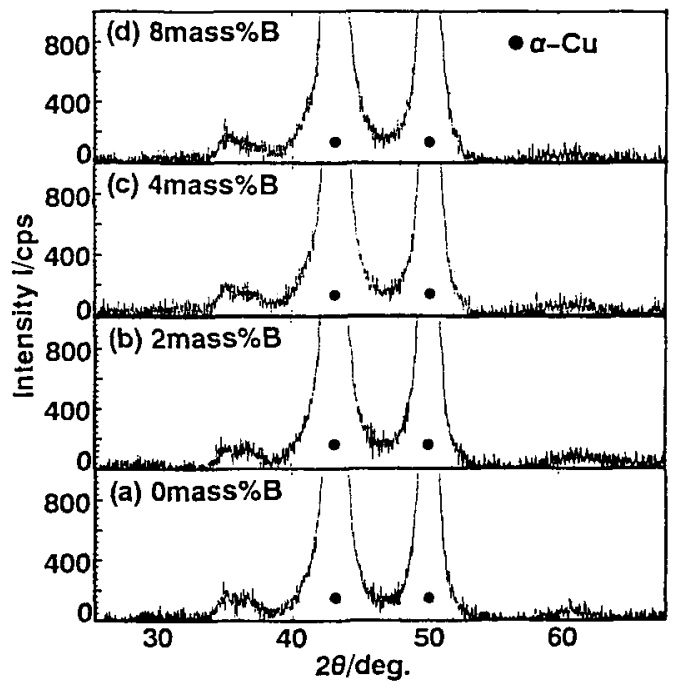

Fig.3 XRD patterns of the powder $\langle A\rangle$ with various boron contents. The powder are as-MA.

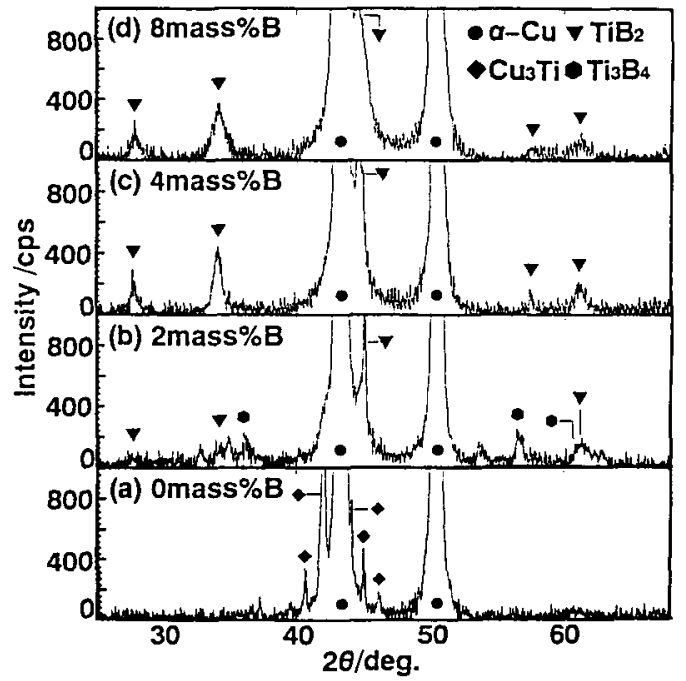

Fig. 4 XRD patterns of the powder $\langle A\rangle$ with various boron contents. The powder was quenched from $1173 \mathrm{~K}$ for $72 \mathrm{ks}$ after MA.

らMAにより36.272〜36.289nmに増大した。これは $\alpha$ 一Cu相中へのTi ${ }^{7>}$ やの固溶によるものと思われるかi， Cuに対するBの原子半径比は0.7 ${ }^{8)}$ と極めて小さく， $\alpha$

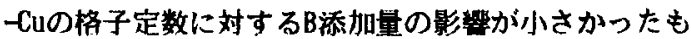
のと思われる。

種々のB量を添加したPowder〈A〉をさらに1173Kで72 $\mathrm{ks}$ 整処理した後のX線回折結果をFig.4に示す．Bを添 加しないCu-8mass\%Ti粉末本では $\alpha$-Cu相の他に平街 $\beta$ 相 であるCu Tiの回折線がみられた，2mass\%B添加した

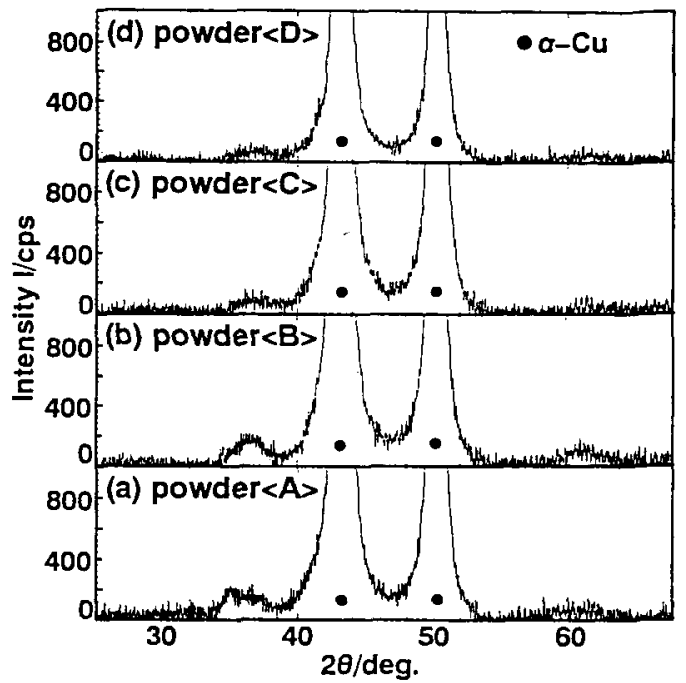

Fig.5 XRD patterns of powder (content of 4mass\%B) of prepared by various processes.

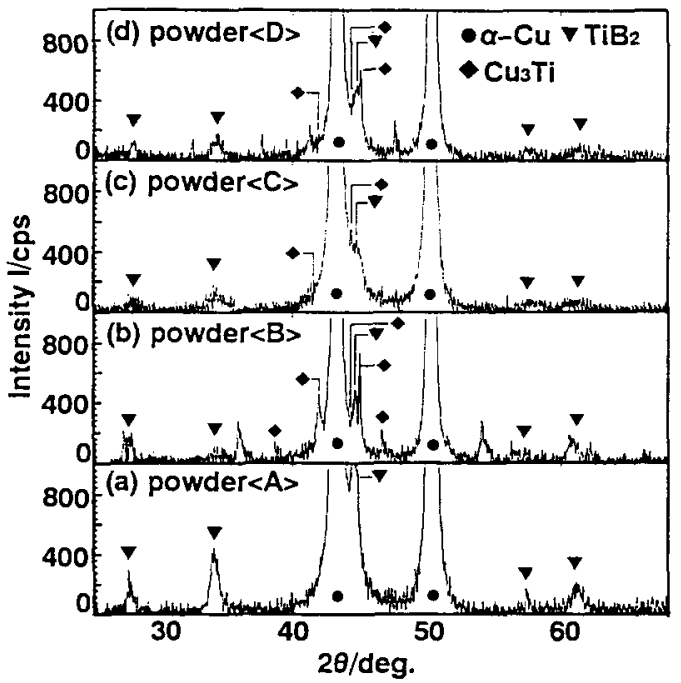

F'ig.6 XRD patterns of various powders (content of $4 \mathrm{mass} \% \mathrm{~B}$ ). The powder was quenched from $1173 \mathrm{~K}$ for $72 \mathrm{ks}$ after $M A$.

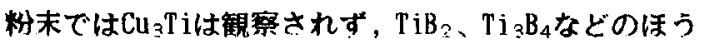
化チタン相が観察された。さらにB添加量が增すとTi $\mathrm{B}_{4}$ は減少しTiB 2 が增加した，したがってBを添加した MA粉末を热姏理すると合金相の析出は減少し，Tiは ほう化物として生成するようになる，そして䭪が少 量であればTi側のほう化チタンとなり，十分な量のB であればTiB 2 が生成するようになると思われる。

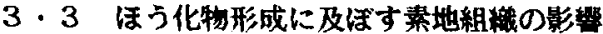

程々の工程で作製した MA粉末のX線回折結果を 
Fig.5に,これらの粉末をさらに1173Kで72ks熱処理し たときの結果をFig.6に示す．いずれの粉末もMA後 では，元素混合粉末から作製したPowder $<A>と$ 同様に， $\alpha$-Cuの回折線と $2 \theta=36 \sim 38 \mathrm{deg}$.に非平衡(Cu-Ti)合金

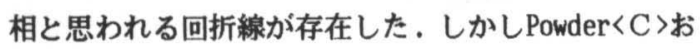
よびPowder $\langle\mathrm{D}>に$ 見られる非平衡合金相の回折線は低 強度であり，このような非平衡相は元素粉末のM A 過 程で生成しやすいものと思われる．またPowderくD>の

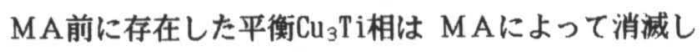
た.これはMA過程で平衡相が分解し,Tiが $\alpha$-Cu相 に固溶し過飽和固溶体となるか, あるいは非平衡相化 または非晶質化したものと思われる．これらのM A粉 末を $1173 \mathrm{~K}, 72 \mathrm{ks}$ の熱処理すると, 素地は $\alpha-\mathrm{Cu}$ と $\mathrm{Cu}_{3}$ $\mathrm{Ti}$ 平衡 2 相組織となり, ほう化千タンはTiB ${ }_{2}$ のかか 生成した.そしてTiB 2 の生成はPowder $<\mathrm{A}$ >が最も著し い. MA段階では，いずれの粉末も素地組織に非平衡 合金相が存在し，ほう化チタンは生成しないかあるい は生成してもその量は僅かであった。したがってこれ らの粉末を熱処理することによって, 非平衡合金相が 平衡相 $\mathrm{Cu}_{3} \mathrm{~T} \mathrm{~T}$ になるとともに, 非平衡相から分解した チタンと添加したBが 固相反応してほう化千タンが生 成・成長するものと考えられる。

1173Kで72ks熱処理したPowder $\langle A$ 〉と Powder $\langle\mathrm{B}>$ の 粒子断面のS EM像をFig.7に示す，いずれの粉末に も数 $\mu \mathrm{m}$ の直径の暗色の粒子と $1 \mu \mathrm{m}$ 以下の明色の粒子 とが分散している.特に, Powder $\langle A>$ 々は明色の粒子 が, Powder $\langle\mathrm{B}>に は$ 暗色の粒子が多く見られる。暗色

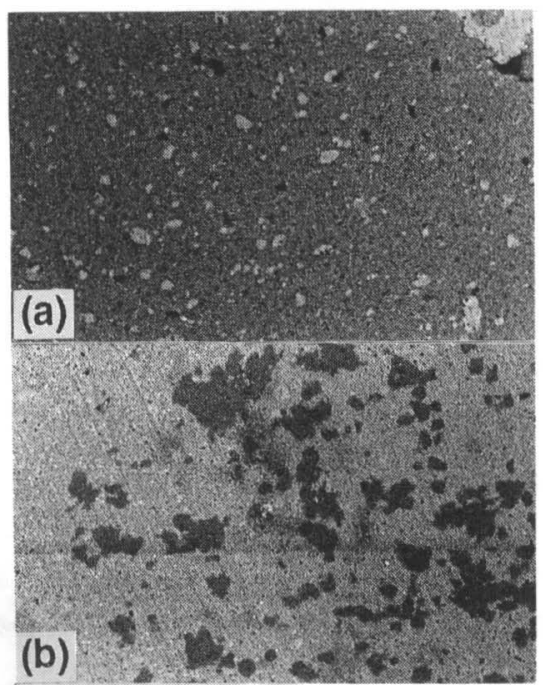

Fig.7 SEM micrographs of sectioned particle of (a) powder $\langle A\rangle$ and (b) powder $\langle B\rangle$ containing of 4 mass\%B. The powder was quenched from $173 \mathrm{~K}$ for $72 \mathrm{ks}$ af ter MA.
の粒子はEPMAの結果, $\mathrm{Cu}_{3} \mathrm{Ti}$ と判断された。明色 の粒子は, X線回折結果より $\mathrm{TiB}_{2}$ と推定される。これ はCu-Ti-Bの混命粉末の反応焼結で牛成するTiB 2 が 織 維状あるいは長針状の形態 ${ }^{5)}$ であるのに対し, M A 粉 末の加熱で生成するTiB 2 は微細な粒子状であることが 特徵と思われる.このような形態の粒子の分散は機械 的强度の向上に有効と思われる。

\section{4 結 言}

(1) Powder $\langle\mathrm{A}>$ ではMAにより非平衡(Cu-Ti)相の牛. 成し, 低B添加量ではTi ${ }_{3} B_{4} や T i B_{2}$ が, 高B添加量では $\mathrm{TiB}_{2}$ が牛成し著しく硽化する，その後の1173K熱好理 により非平衡(Cu-Ti) 相は消滅し, ほう化千タンの牛 成・成長により再び硬化する。

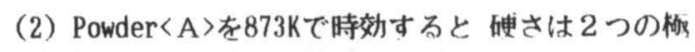
大值を持って変化する。初期の硬化量はB添加量に依 存しないが, 後期のの硬化量は高B添加量ほと大きい.

(3) Powder〈B〉では, 非平衡(Cu-Ti)相が生成する.

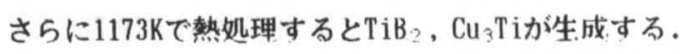

(4) Powder $\langle\mathrm{C}\rangle$ おびPowder $\langle\mathrm{D}>$ では非平衡(Cu-Ti ) 相が牛成するが, その量は少ない,また，ほう化チ夕 ンはほとんど生成しない，これを1173Kで加熱处棵す るとTiB 2 が牛成し，素地は $(\alpha+\beta) 2$ 相組糡となる.

\section{謝 辞}

本研究の一部は文部省科学研究費補助金より研究助 成を受けたことを記し、ここに感謝の意を表します。

\section{文献}

1)師岡利政, 湯浅栄二, 松本修: 粉体および粉末治金, 39(1992), 202.

2)E.Yuasa, T.Morooka, R.Laag, W.A.Kaysser and G. Petzow: Powder Metallury, 35(1992), 120.

3)師闭利政, 湯浅栄二, 松本修: 粉体および粉末治金, 40(1993), 100.

4)師岡利政, 湯浅栄二, 松本修, 角田誠 : 粉体およひ 粉末冶金, 40(1993), 256.

5)橋本やす彦, 大森慎一郎, 香山こう一郎 : 粉体およ び粉末治金, 33(1986), 302 .

6)A.Calka and A.P.Radlinski : Less-Common Metals, 161(1990), L23.

7)佐治重舆, 池野進, 堀重徳：日本金属学会誌, 42 (1978), 63.

8)日本金属学会編：金属データブック, 丸善, 8 . 